\title{
Community treatment orders: towards a new research agenda
}

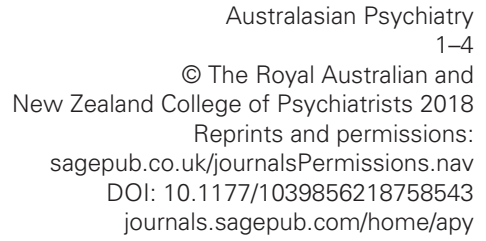
journals.sagepub.com/home/apy

@SAGE

\begin{abstract}
Lisa Brophy Associate Professor, Melbourne School of Population and Global Health, Centre for Mental Health, University of Melbourne, Melbourne, VIC, and; Principal Research Fellow, Research, Development and Advocacy, Mind Australia, Heidelberg, VIC, Australia

Vrinda Edan Consumer Academic, Monash University, Southern Synergy, Dandenong Hospital, Dandenong, VIC, Australia

Piers Gooding Postdoctoral Research Fellow, Melbourne Law School, Melbourne Social Equity Institute, University of Melbourne, Melbourne, VIC, Australia

Bernadette McSherry Foundation Director, Melbourne Social Equity Institute, University of Melbourne, Melbourne, VIC, and; Adjunct Professor of Law, Melbourne Law School and Adjunct Professor of Law, Faculty of Law, Monash University, Clayton, VIC, Australia
\end{abstract}

Tatum Burkett Former Research Assistant, Melbourne Social Equity Institute, University of Melbourne, Melbourne, VIC, Australia

Sue Carey Psychiatrist, Mental Health Tribunal, Melbourne, VIC, Australia

Andrew Carroll Associate Professor (Adjunct), Centre for Forensic Behavioural Science, CFBS, Swinburne University, Hawthorn, VIC, Australia

Sascha Callaghan Lecturer, Sydney Law School, University of Sydney, Sydney, NSW, Australia

Anne Finch Engagement Officer, Tandem, Melbourne, VIC, Australia

Margaret Hansford Founder, Partnership Solutions, Melbourne, Melbourne, VIC, Australia

Sarah Hanson Executive Officer, Mental Health Commission of New South Wales, Sydney, NSW, Australia

Steven Kisely Professor of Psychiatry, Faculty of Medicine, Princess Alexandra Hospital Southside Clinical Unit, University of Queensland, St Lucia, QLD, Australia

Sharon Lawn Professor, Department of Psychiatry, Faculty of Medicine Nursing and Health Sciences, Flinders Human Behaviour and Health Research Unit, Flinders University, Adelaide, SA, Australia

Edwina Light Postdoctoral Research Fellow, Sydney Health Ethics, University of Sydney, Sydney, NSW, Australia

Sean Maher Legal Research Officer, Royal Australian and New Zealand College of Psychiatrists, Melbourne, VIC, Australia

Gunvant Patel Consultant Psychiatrist, Forensicare, Melbourne, VIC, Australia

Christopher James Ryan Clinical Associate Professor, Department of Psychiatry, Sydney Medical School and Sydney Health Ethics, University of Sydney, Westmead Hospital, Westmead, NSW, Australia

Keir Saltmarsh Senior Education and Engagement Officer, Mental Health Complaints Commissioner, Melbourne, VIC, Australia Anthony Stratford Senior Advisor Lived Experience, Mind Australia, Heidelberg, VIC, Australia

Juan Jose Tellez Research Assistant, Graduate School of Education, Melbourne Social Equity Institute, University of Melbourne, Melbourne, VIC, Australia

Maggie Toko Chief Executive Officer, Victorian Mental Awareness Council, Brunswick, VIC, Australia

Penelope Weller Associate Professor, Graduate School of Business and Law, RMIT University, Melbourne, VIC, Australia

\begin{abstract}
Objectives: The aim of this study was to report on a half-day multi-stakeholder symposium on community treatment orders (CTOs) hosted by the Melbourne Social Equity Institute (MSEI), which identified research gaps and opportunities, and produced an agreed agenda for future CTO research.
\end{abstract}

Corresponding author:

Juan Jose Tellez, University of Melbourne Graduate School of Education, Melbourne Social Equity Institute, 201 Grattan Street, Carlton, Melbourne, VIC 3053, Australia.

Email: juan.tellez@unimelb.edu.au 
Methods: The MSEI convened a symposium for 22 experts in CTO research to discuss research priorities in this field in Australasia. An independent moderator elicited views and recommendations and produced a report detailing possible research projects.

Results: Research on CTOs is contentious and there is a need to gather and examine information regarding both their use and utility. Due to the complexities involved, it was agreed that research should be undertaken in partnership with persons with had lived experience of mental health problems, clinicians, policymakers and other interdisciplinary stakeholders. Five key areas for future investigation were identified.

Conclusions: The issues and recommendations arising from the symposium should shape the scope, nature and conduct of future research directions in the field.

Keywords: community treatment orders, compulsory treatment, mental health legislation, civil commitment laws, human rights

$\mathrm{M}$ ental health legislation in Australia and New Zealand authorises compulsory treatment by way of community treatment orders (CTOs). The justification usually advanced for using CTOs is that they provide treatment in a less restrictive environment to that of inpatient psychiatric services. However, evidence for the efficacy of CTOs is mixed and their use challenges human rights frameworks for mental health law and policy reform. ${ }^{1,2}$

The United Nations Committee on the Convention on the Rights of Persons with Disabilities (CRPD) has recommended that the Australian Government repeal legislation that allows for the use of CTOs and has made similar observations in relation to New Zealand. , $^{3,4}$

Since 2013, seven Australian jurisdictions have either repealed and replaced, or made significant changes to their mental health legislation, but all Australian jurisdictions have retained powers to make CTOs. New Zealand's legislation enabling compulsory community treatment has remained the same over 25 years. ${ }^{5}$ The relevant mental health legislation relating to CTOs in Australasia is summarised in Table 1.
Advancements in local and international law and policies, together with contemporary research and commentary, have raised questions about the objectives, ethics and efficacy of CTOs. ${ }^{7}$ The Melbourne Social Equity Institute (MSEI) held a symposium on 27 May 2016 to explore the scope, nature and conduct of future research.

\section{Method}

The MSEI is a 'virtual' institute at the University of Melbourne which supports interdisciplinary research. The institute facilitated meetings between the four lead authors (LB, VE, PG, BM) who identified individuals with expertise in the area in line with snowball sampling. ${ }^{8}$ The MSEI then provided invitees with an opportunity to nominate additional attendees.

The symposium brought together 22 participants from across Australia and New Zealand and was moderated by another author $(\mathrm{MH})$ - an independent facilitator with 25 years' experience. Participants included three members of non-government mental health organisations, three who identified as consumer representatives, one

Table 1. Australasian Mental Health Acts and provisions for community treatment orders

\begin{tabular}{llll}
\hline Jurisdiction & Act & Name of order & Provisions \\
\hline ACT & Mental Health Act 2015 & Community Care Order & Chapter 5, Part 5.5 \\
NSW & Mental Health Act 2007 & Community Treatment Order & Chapter 3, Part 3 \\
NT & Mental Health and Related Services & Community Management Order & Part 7 \\
& Act 1998 & & \\
OLD & Mental Health Act 2016 & Treatment Authority (Community) & Chapter 2, Part 4 \\
SA & Mental Health Act 2009 & Community Treatment Order & Part 4 \\
TAS & Mental Health Act 2013 & Treatment Ordera & Chapter 2, Part 3, Division 2 \\
VIC & Mental Health Act 2014 & Community Treatment Order & Part 4, Division 4 \\
WA & Mental Health Act 2014 & Community Treatment Order & Part 8 \\
New Zealand & Mental Health (Compulsory & Community Treatment Order & Part 2, Section 29 \\
& Assessment and Treatment) Act 1992 & & \\
\hline
\end{tabular}

aWhile the term 'community' is not mentioned in the Mental Health Act 2013(TAS), Section 42(1) refers to treatment orders as encompassing giving 'the treatment specified in the order and referred to in the treatment plan for the patient'. The Tasmanian Department of Health and Human Services' guide for clinicians clarifies that this may occur in the community. ${ }^{6}$ 
member of a carers' organisation, five psychiatrists, eight academics and two representatives from government departments. The academics had backgrounds in law, psychology, nursing, social work and the arts. Three of the psychiatrists could also be considered academics.

Participants were separated into small groups and asked to document their discussions on key issues, identify research opportunities and consider the characteristics of successful research projects. Mind maps were used to illustrate small-group outcomes, and these were subsequently discussed with all participants. ${ }^{9}$ Individual attendees were also able to record additional ideas arising during discussions. The moderator ensured themes and recommendations could be collated in a way that was broadly representative and enabled an overarching consensus to be reached, which took the views of individual participants into account. Following the symposium, the moderator provided the MSEI with a comprehensive report of the findings and a transcript of outcomes which were provided to participants for comments.

\section{Results \\ Key gaps in existing research}

There was a consensus that more evidence is needed regarding the patterns of CTO use and associated demographics. Recent Australian Institute of Health and Welfare data indicate that there is significant variation in the reported percentages of people who access mental health services under CTOs across Australian jurisdictions. In 2014-2015, proportions ranged from 3\% in Western Australia to $14.6 \%$ in Victoria, and $23.7 \%$ in Queensland. ${ }^{10}$ The use of CTOs in Australia is high by world standards. ${ }^{11}$ In New Zealand, the number of people subject to a CTO on any given day increased by $41 \%$ between 2009 and 2015, from 61 per 100,000 to 86 per 100,000 . Moreover, the rates at which people are subject to CTOs across the various district health boards vary by up to a factor of four. ${ }^{12}$

Participants discussed a range of often competing factors that potentially influence the prevalence of CTOs. These include:

- the effect of the United Nations CRPD ${ }^{13}$;

- variances in mental health legislation in all Australasian jurisdictions;

- the Australian National Framework for RecoveryOriented Mental Health Services ${ }^{14}$;

- environmental factors, including population sizes and demographics;

- the (in)accessibility of inpatient beds and clinical community-based resources, in addition to the need to secure services and supports;

- the costs of making, administering and reviewing CTOs;

- operational policies; and

- peer and service culture.
There was a broad consensus that there is paucity of empirical evidence as to whether CTOs achieve beneficial outcomes. Since the symposium was held, the UK's National Institute for Health Research published a report on the outcomes of the Oxford Mental Health Coercion Programme (OMHCP). The OMHCP comprised three studies, including the Oxford Community Treatment Order Evaluation Trial (OCTET). The OCTET involved a randomised controlled trial (RCT) that took place between 2008 and 2012, comparing treatment on CTOs to treatment during periods of leave. The report concluded that 'CTOs do not confer any benefits' (Burns et al. ${ }^{7}$, p.263). No comparable trial has been conducted in Australasia.

\section{Future research}

Symposium participants identified a need for further interdisciplinary research in the field that is co-designed and co-produced by people with lived experience of mental health problems. There was broad consensus that consumers, families and carers can contribute expertise and perspectives, and that the co-design and co-production of research of this kind is essential. This was echoed in a recent commentary from the UK's McPin Foundation in December 2016. ${ }^{15}$ The foundation highlights the need for 'patient and public' involvement in projects, and the need to move away from 'tokenism' towards meaningful roles, particularly with respect to the roles of mental health service users.

Participants discussed the potential benefits of, and opportunities for, the use of less restrictive models, including case management and assertive community treatment, noting a lack of data demonstrating how treatment outcomes (including consumer experiences and readmission rates) compare between models. There was an emphasis on the need for holistic, streamlined care, promoting recovery-oriented service delivery and achieving consumer empowerment. ${ }^{16,17}$

The MSEI subsequently brought together an interdisciplinary research team which reviewed the report by the independent facilitator (author $\mathrm{MH}$ ) and identified five potential projects for further research:

1. A scoping study on the use of CTOs across jurisdictions, which includes demographic data of those placed on CTOs and rationales for CTO use.

2. A RCT comparing the use of CTOs with voluntary assertive community treatment and/or other alternatives to CTOs.

3. A qualitative study exploring personal and cultural narratives from persons placed on CTOs.

4. A study of the effect of peer advocacy on the use of CTOs.

5. The impact of the national recovery framework and human rights principles in legislation on mental health tribunal members' decision-making concerning CTOs. 
The research team explored the feasibility of each of these options. Of these, the first identified project, the scoping study, was the initial priority. The plan is to gather and analyse current public health administrative data concerning the socio-economic demographics and clinical features of those placed on CTOs across Australasia. As well as data analysis, the team plans to develop an online survey, run focus groups and carry out individual interviews to identify the reasons for making CTOs and compare them with legislative criteria for their use.

The other proposed projects raise several research challenges. In relation to the second project, three major $\mathrm{RCTs}^{18-20}$ on CTOs have been conducted internationally, the approaches for which could provide a starting point for similar research in Australia. However, these studies have been criticised on methodological grounds and RCTs may also present difficulties in the generalisability of their results because of the varying contexts in which CTOs are implemented. ${ }^{21}$ In addition, RCTs present ethi$\mathrm{cal}$ and resource challenges that require significant, broadranging support that may not be feasible when CTOs are so embedded in practice in Australia and New Zealand.

In relation to the final three projects, several qualitative studies in relation to the views of those placed on CTOs have already been conducted, ${ }^{22,23}$ although there continues to be considerable interest in the impact of CTOs on people subject to them and gaps in knowledge about certain groups, such as people who have experienced other coercive state interventions. Therefore, careful consideration would need to be given to the focus of future new studies. There are also challenges in developing a rigorous methodology for defining and measuring the effect of peer advocacy on the use of CTOs and the impact of recovery and human rights frameworks on mental health tribunal members' decision-making. Nevertheless, this consensus process for identifying research priorities helps provide a starting point for exploring what has been termed an 'invisible' part of mental health policy and practice. ${ }^{11}$

\section{Conclusion}

This paper reports on the issues raised during a multistakeholder symposium on CTOs. It is hoped that future research will add to Australasia's knowledge base regarding the objectives, ethics and efficacy of CTOs. Symposium participants agreed that future research should be interdisciplinary and facilitate co-design and co-production. In addition, such research should aim to provide an evidence base for reforms to clinical practice, service delivery and public policy that reflect the knowledge of all key stakeholders.

\section{Disclosure}

The authors report no conflict of interest. The authors alone are responsible for the content and writing of the paper.

\section{Funding}

The symposium was funded by the Melbourne Social Equity Institute at the University of Melbourne, Australia.

\section{References}

1. Rugkåsa J. Effectiveness of community treatment orders: the international evidence. Can J Psychiatry 2016; 61: 15-24.

2. Newton-Howes $G$ and Ryan CJ. The use of community treatment orders in competent patients is not justified. Br J Psychiatry 2017; 210: 311-312.

3. Committee on the Rights of Persons with Disabilities. Concluding observations on the initial report of Australia, 10th session. UN Doc CRPD/C/AUS/CO/1, 4 October 2013.

4. Committee on the Rights of Persons with Disabilities. Concluding observations on the initial report of New Zealand, 12th session. UN Doc CRPD/C/NZL/CO/1, 31 October 2014.

5. O'Brien AJ. Community treatment orders in New Zealand: regional variability and international comparisons. Australas Psychiatry 2014; 22: 352-356.

6. Tasmanian Government. Tasmania's Mental Health Act 2013: a guide for clinicians. Hobart: Department of Health and Human Services, 2014.

7. Burns T, Rugkåsa J, Yeeles K, et al. Coercion in mental health: a trial of the effectiveness of community treatment orders and an investigation of informal coercion in community mental health care. Programme Grants for Applied Research. Southampton (UK): NIHR Journals Library, 2016.

8. Oliver P. Snowball sampling. In: Jupp V (ed) The SAGE dictionary of social research methods. London: SAGE Publications Ltd, 2006, p.282.

9. Wheeldon J and Åhlberg M. Visualizing social science research: maps, methods, and meaning. Thousand Oaks, CA: SAGE Publications, Inc, 2012.

10. Australian Institute of Health and Welfare. State and territory community mental health services - Table CMHC.23, http://mhsa.aihw.gov.au/services/community-care/ (2016, accessed 2 June 2017).

11. Light EM, Kerridge IH, Ryan CJ, et al. Community treatment orders: rates and patterns of use. Australas Psychiatry 2012; 20: 478-482.

12. Ministry of Health, New Zealand. Office of the Director of Mental Health Annual Reports, https://www.health.govt.nz/about-ministry/corporate-publications/mentalhealth-annual-reports (2006-2015, accessed 2 June 2017).

13. Convention on the Rights of Persons with Disabilities, GA Res 61/106, opened for signature 30 March 2007, UN Doc A/Res/61/611, entered into force 3 May 2008.

14. Department of Health, Commonwealth of Australia. A national framework for recoveryoriented mental health services, http://www.health.gov.au/internet/publications/publishing.nsf/Content/mental-pubs-n-recovgde-toc (2013, accessed 19 June 2017).

15. Morgan K. Patient and public involvement in research, why not?, http://mcpin.org/wpcontent/uploads/talking-point-paper-2.pdf (2016, accessed 19 June 2017).

16. Bond GR and Drake RE. The critical ingredients of assertive community treatment. World Psychiatry 2015; 14: 240-242.

17. Dawson $S$, Lawn $S$, Simpson A, et al. Care planning for consumers on community treatment orders: an integrative literature review. BMC Psychiatry 2016; 16: 394.

18. Burns T, Rugkåsa J, Molodynksi A, et al. Community treatment orders for patients with psychosis: a randomised controlled trial (OCTET). Lancet 2013; 381: 1627-1633.

19. Swartz M, Swanson JD, Wagner HR, et al. Can involuntary outpatient commitment reduce hospital recidivism? Findings from a randomized trial with severely mentally ill individuals. Am J Psychiatry 1999; 156: 1968-1975.

20. Steadman HJ, Gounis K, Dennis D, et al. Assessing the New York City involuntary outpatient commitment pilot program. Psychiatric Serv 2001; 52: 330-336.

21. Swartz MS and Swanson JW. Randomised controlled trials and outpatient commitment. Lancet Psychiatry 2017; 4(12): e30.

22. Dawson J. Community treatment orders: international comparisons, http://www.otago. ac.nz/law/research/otago036152.pdf (2005, accessed 20 December 2017).

23. Brophy $L$ and McDermott $F$. what's driving involuntary treatment in the community? The social, policy, legal and ethical context. Australas Psychiatry 2003; 11(suppl 1): S84-S88. 